Original Research Article

\title{
Seroprevalence and trends of transfusion transmissible infections among voluntary and replacement donors-an institutional retrospective study
}

\author{
Meena S. ${ }^{1}$, Maheshwari V. ${ }^{2}$, Gupta D. ${ }^{3}$ \\ ${ }^{1}$ Dr. Santosh Meena, Assistant Professor, Department of Pathology, ${ }^{2}$ Dr. Veena Maheshwari, Assistant Professor, \\ Department of Microbiology, ${ }^{3}$ Dr. Deepti Gupta, Assistant Professor, Department of Pathology, RKDF MCH \& RC, \\ Bhopal, MP, India.
}

Corresponding Author: Dr. Veena Maheshwari, Assistant Professor, Department of Microbiology, RKDF MCH \& RC, Bhopal. E-mail: mail2veenam@yahoo.co.in

\begin{abstract}
Introduction: Transfusion transmitted infections are major problem associated with blood transfusion. There are several infectious as well as non-infectious risks associated with transfusion of blood. Aim and Objective: The present study was carried out to find out the sero-prevalence and changing trends of various TTIs in blood donors. Material and Methods: A record based study was conducted from January 2008- December 2010. Data were collected from therecords of blood bank which also included data of blood donation camps. Data regarding sex, screening testresults and type of donors were collected from the records. Results: Out of 17640 donors, voluntary donors (78.4\%) were more in comparison to replacement donors (21.6\%). Out of all TTIs, prevalence of HBV $(2.14 \%)$ was highest followed by, HCV $(0.66 \%)$, HIV $(0.6 \%)$, Malaria $(0.14 \%)$ and Syphilis $(0.05 \%)$. TTIs were more prevalent in replacement donors than voluntary donors. The number ofvoluntary donors has fallen from $2008-2010$, but there is male preponderance in both voluntary and replacement donors. Conclusion: From results it has been concluded that prevalence of transfusion transmitted infection (HIV, HBV, HCV, VDRL, and malaria) was more in replacement donors in comparison to voluntary donors. With the implementation of strict donor selection criteria, use of sensitive screening tests and establishment of strict guidelines for blood transfusion it may be possible to reduce the incidence of transfusion transmitted infection in the Indian scenario.
\end{abstract}

Key words: Seroprevalence, Transfusion-transmitted infection, Replacement donors, Voluntary donors

\section{Introduction}

A well organised blood transfusion service is a vital component of patient management in any health care delivery system. When used correctly it can save life, nevertheless in addition it carries the risk of transmission of wide number of infectious agents as well. It has been estimated that every two seconds someone needs blood [1] andone-third of all patients admitted to intensive care units (ICUs) in the developed world receive a blood transfusion [2]. According to WHO, safe blood is a universal right, Globally, more than 81 million units of blood is donated annually. More than 18 million units of blood are not screened for these transfusiontransmissible infections. With every unit of blood transfused, there is a $1 \%$ risk of transfusion associated problems including transfusion transmitted diseases [3].

Manuscript received: $14^{\text {th }}$ July 2018

Reviewed: $24^{\text {th }}$ July 2018

Author Corrected: $30^{\text {th }}$ July 2018

Accepted for Publication: $2^{\text {nd }}$ August 2018
Transfusion transmitted infections (TTIs) are a major problem associated with blood transfusion An integrated strategy for blood safety is required for elimination of these transfusion transmitted infections and for provision of safe and adequate blood transfusion services to the people. The main component of an integrated strategy include collection of blood only from voluntary non-remunerated blood donors, but this mode of collection though ideal is not always practically implementable in our country due to various factors such as illiteracy, negative attitudes towards blood donation, and fear of weakness and disease.

Due to these factors our blood banks depend also on replacement donation which is not entirely voluntary, as the patients relatives are under pressure to replace the blood transfused to the patient. . Voluntary donors are preferred over replacement donors because replacement donor may tend to conceal some history with the 
intention of benefitting their patient, out of ignorance that they are putting someone's life at risk [4]

There are basically 3 types of blood donors: voluntary/ unpaid; family/replacement and paid.

1. Voluntary non-remunerated donors: A donor who gives blood, plasma or other blood components freely and voluntarily without pursuing any remuneration.

2. Family / family replacement donors: A donor who gives blood when it is required by a member of donor family or community.

3. Commercial/professional/paid donors: A donor who gives blood in return for money or other form of payment.

There are four main groups of micro-organisms known to cause infections namely viruses, bacteria, protozoa and fungi. There is a long list of the first three groups of microbes namely - viruses, bacteria and protozoa reported to be transmitted by blood transfusion. Individuals with fungal infections are usually too sick to be accepted as blood donors. Among them, important transfusion transmitted viruses are human immunodeficiency virus (HIV-I/II), hepatitis B virus (HBV), hepatitis $\mathrm{C}$ virus (HCV), syphilis infection by Spirochetes, and transfusion associated malaria infection

It is important to note that the problem of TTIs is directly proportionate to the prevalence of Infections among the blood donor community. Thus the present study was conducted with an aim to assess the percentage ofvoluntary as well as replacement blood donors and to find out the sero-prevalence and changing trends ofvarious TTIs among blood donors.

\section{Original Research Article}

\section{Materials and Methods}

Place and Type of Study: This retrospective crosssectional study was carried out at the Blood Bank of Sir J.J Group of Hospital, Grant Medical College, Mumbai. Institutional clearance was obtained from the ethical committee of the hospital.

Sampling Methods and Collection: Data were collected from the records of the blood bank from January 2008- December 2010.Donors were carefully screened by trained personnel after a complete physical examination and satisfactorily answering the donor's questionnaire.

Inclusion Criteria: The study was conducted on all voluntary and replacement donors for a period of three years from January 2008 to December 2010. Written consent was also taken from them prior to donation.

A total of 17640 blood units (Voluntary and replacement) were collected from January 2008 to December 2010.

Exclusion Criteria: For blood donation were age $<18$ years and $>60$ years, weight $<45 \mathrm{~kg}$, current history of medication, recent blood transfusion, any infection, anaemia and recent history of any surgical procedure.

Data regarding voluntary blood donation at the blood bank as well as various blood donation camps organized by the blood bank were analyzed. In the blood bank each donor blood sample was screened for five infections - HIV, HBV, HCV, Syphilis and Malaria. Donor blood was screened for HIV, HBV, HCV, Syphilis and malarial parasite using rapid kits and ELISA.

\section{Results}

During the study period, a total of 17640 donors were screened during the three-year period from January 2008December 2010 for TTIs. Among them, 15770 (89.4\%) were males and 1870 (10.4\%) were females. A total of 13820 (78.4\%) were voluntary donors which included donors at the blood bank of J.J. Hospital, Mumbai and also donors at the blood camps organized by the blood bank. and 3820 (21.6\%) were replacement donors.

Table-1: Sex wise distribution of Voluntary donors.

\begin{tabular}{|c|c|c|c|}
\hline \multirow{2}{*}{ Year } & \multicolumn{2}{|c|}{ Voluntary Donors } & \multirow{2}{*}{$\begin{array}{c}\text { Total Voluntary } \\
\text { Donors No. (\%) }\end{array}$} \\
\cline { 2 - 3 } & Male No. (\%) & Female No. (\%) & $12490(100 \%)$ \\
\hline 2008 & $10871(87.03 \%)$ & $1619(12.96 \%)$ & $494(100 \%)$ \\
\hline 2009 & $415(84.00 \%)$ & $79(15.99 \%)$ & $836(100 \%)$ \\
\hline 2010 & $740(88.51 \%)$ & $96(11.48 \%)$ & $13820(100 \%)$ \\
\hline Total & $12026(87.01 \%)$ & $1794(12.98 \%)$ & 0 \\
\hline
\end{tabular}

Out of 13820 voluntary donors 12026 (87.0\%) were males and 1794 (13\%) were females. Among the 3820 replacement donors, $3744(98.0 \%)$ were males and $76(2.0 \%)$ were females. 


\section{Original Research Article}

Table-2: Sex wise distribution of Replacement Donors.

\begin{tabular}{|c|c|c|c|}
\hline \multirow[t]{2}{*}{ Year } & \multicolumn{2}{|c|}{ Replacement Donors } & \multirow{2}{*}{$\begin{array}{c}\text { Total Replacement } \\
\text { Donors No. (\%) }\end{array}$} \\
\hline & Male No. (\%) & Female No. (\%) & \\
\hline 2008 & $2414(96.94 \%)$ & $76(3.05 \%)$ & $2490(100 \%)$ \\
\hline 2009 & $800(100 \%)$ & $0(0.00 \%)$ & $800(100 \%)$ \\
\hline 2010 & $530(100 \%)$ & $0(0.00 \%)$ & $530(100 \%)$ \\
\hline Total & $3744(98.01 \%)$ & $76(1.98 \%)$ & $3820(100 \%)$ \\
\hline
\end{tabular}

This shows the predominance of males as compared to females in blood donation during the study (Table 1\&2)

Table-3: Year wise trend of Sero-prevalence of TTIs from 2008-2010.

\begin{tabular}{|c|c|c|c|c|c|c|}
\hline Year & Number of donors & HIV & HBV & HCV & Syphilis & Malaria \\
\hline 2008 & 6774 & $36(0.55 \%)$ & $171(0.52 \%)$ & $35(0.52 \%)$ & $2(0.03 \%)$ & $5(0.07 \%)$ \\
\hline 2009 & 6055 & $35(0.58 \%)$ & $123(2.03 \%)$ & $41(0.68 \%)$ & $2(0.03 \%)$ & $20(0.33 \%)$ \\
\hline 2010 & 4811 & $34(0.7 \%)$ & $85(1.77 \%)$ & $41(0.82 \%)$ & $2(0.04 \%)$ & $0(0.00 \%)$ \\
\hline Total & 17640 & 105 & 379 & 117 & 6 & 25 \\
\hline \multicolumn{2}{|c|}{ Percentage of individual } \\
infection
\end{tabular}

The year wise proportion (in percentages) of different TTIs among blood donors has been shown in (Table 3). With respect to individual TTIs, it was observed that out of total 17640 donors screened, the maximum number of donors 379 were found positive for HBV infection followed by 117 donors for HCV, 105 donors test positive for HIV, 25 donors for malaria and 6 donors test positive for syphilis.

Thus the proportion (in percentages) of TTIs among blood donors at blood bank during three year period was found maximum for HBV $(2.14 \%)$ followed by HCV $(0.66 \%)$, HIV $(0.6 \%)$ malaria $(0.14 \%)$ and least for syphilis $(0.05 \%)$.

Table-4: Distribution of seropositive cases in voluntary donors (VD) and Replacement donors (RD).

\begin{tabular}{|c|c|c|c|c|c|c|c|c|c|c|}
\hline \multirow{2}{*}{ Year } & \multicolumn{2}{|c|}{ HIV } & \multicolumn{2}{|c|}{ HBsAg } & \multicolumn{2}{|c|}{$\mathrm{HCV}$} & \multicolumn{2}{|c|}{ Syphilis } & \multicolumn{2}{|c|}{ Malaria } \\
\hline & VD & RD & VD & RD & VD & RD & VD & RD & VD & RD \\
\hline 2008 & 7 & 29 & 57 & 114 & 15 & 20 & 1 & 1 & 2 & 3 \\
\hline 2009 & 4 & 31 & 18 & 105 & 6 & 35 & 0 & 2 & 4 & 16 \\
\hline 2010 & 9 & 25 & 25 & 60 & 11 & 30 & 0 & 2 & 0 & 0 \\
\hline Total & 20 & 85 & 100 & 279 & 32 & 85 & 1 & 5 & 6 & 19 \\
\hline Grand Total & \multicolumn{2}{|c|}{105} & \multicolumn{2}{|c|}{379} & \multicolumn{2}{|c|}{117} & \multicolumn{2}{|c|}{6} & \multicolumn{2}{|c|}{25} \\
\hline
\end{tabular}

Out of 12118 screened donors, overall 632 (3.58\%) were seropositive cases. Overall, prevalence of Hepatitis B was highest among all TTIs tested followed by hepatitis C, HIV, malaria and syphilis respectively.

Seropositivity for all TTIs was higher among replacement donors than voluntary donors. Pattern of TTIs with respect to donors dpeicted high prevalence of TTIs in replacement donors as compared to voluntary donors.

Out of 105 HIV positive cases (Replacement Donors = 85, Voluntary Donors = 20); 379 HBV cases (RD=279, VD=100); $117 \mathrm{HCV}$ cases $(\mathrm{RD}=85, \mathrm{VD}=32) ; 6$ Syphilis cases $(\mathrm{RD}=5, \mathrm{VD}=1) ; 25$ Malaria cases $(\mathrm{RD}=19, \mathrm{VD}=6)$

(Table 4). 
Original Research Article

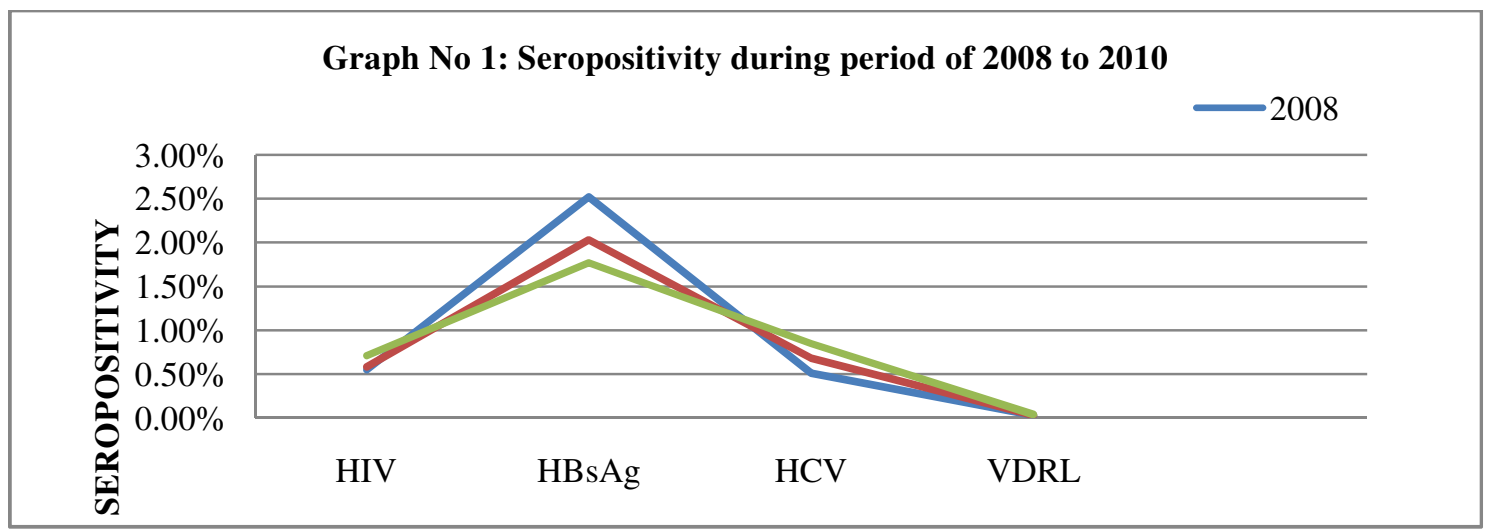

Our study showed a rising trend of HIV and HCV infections among blood donors from $0.55 \%$ in 2008 to $0.71 \%$ in 2010 for $\mathrm{HIV}$, from $0.51 \%$ in 2008 to $0.85 \%$ in 2010 for $\mathrm{HCV}$ respectively. There is decreasing trend for $\mathrm{HBs} \mathrm{Ag}$ from $2.52 \%$ in 2008 to $1.77 \%$ in 2010 and stationary trend for VDRL from $0.03 \%$ to $0.04 \%$ in 2010 . This year wise changing trend of seroprevalence of individual TTI's from Jan 2008 to December 2010 is plotted in Graph 1.

Total number of donors per year was 6774, 6055 and 4811 from January 2008 to December 2010 respectively

\section{Discussion}

Blood transfusion is an essential component of modern health care system when used optimally saves millions of lives every year. Clinical usage of blood should be based on national guidelines; taking the individual patient's needs into consideration, with minimum cost and wastage, optimum safety and efficacy [3].

Every country needs to meet its requirements for blood and blood products and ensure safe blood supplies that are free from HIV, hepatitis viruses and other lifethreatening infections which can be potentially transmitted through unsafe transfusion practices.

Despiteof counseling and medical tests, conducted prior to blood donation, the presence of TTIs is inevitable in donated blood. Since a person can transmit infections during its asymptomatic phase (window period), transfusions can contribute to an ever-widening pool of infection in the general population. Extensive donor selection and sensitive screening tests will help in improving the blood safety and hence ensure the elimination, or at least reduction, of the risk of acquiring TTIs.

Blood safety is integral to the WHO HIV/AIDS plan to combat the spread of HIV infection and to the achievement of the health-related Millennium Development Goals to reduce child mortality, improve maternal health, combat HIV and develop global partnership for development [5].

Accurate estimates of risk of TTIs are important for monitoring safe blood supply and in evaluating the efficacy of the currently employed screening procedures "[6].
The prevalence of TTIs among blood donors in a structured health care system with a well-organized blood establishment can be used as a statistical tool for against those infectious agents that can be transmitted through blood and blood products and hence forth can contribute to statistical estimation of these viruses in the general population "[7].

WHO promotes voluntary over replacement donation. In the presentstudy, $78.4 \%$ were voluntary and $21.6 \%$ were replacement donors. Similar predominance of voluntary donors was noted byShah et al [8] in their study. This reflects the presence ofblood donation awareness among the general population. In a study done inwestern Ahmedabad by Patel et alvoluntary blood donors were reported as $95.56 \%$ [9], but a study from Karnataka and from Haryana reported it as 58\% and $31.4 \%$ respectively $[10,11]$. People should be motivated to become voluntary blood donors for which blood camps are organized.

In our study, males (89.4\%) outnumbered females $(10.4 \%)$. This is similar to other studies done in India by Pallavi $P$ et al., in which $97.84 \%$ were males [12], by Patel PA et al., in which $85 \%$ were males [9], by Arora D et al., in Southern Haryana [11], by Singh K et al., in Coastal Karnataka [13] noting more than $90 \%$ of the male donors.

The present study revealed that TTIs were more prevalent in replacement donors than voluntary donors. Similar observations with high sero-positivity in replacement donors was observed by Singh et al[14] and Pahuja et al [15]. On the other hand Chandra et al. [16] have found almost negligible infectivity rate in 


\section{Original Research Article}

voluntary donors and also no voluntary donor was found to be positive for HIV by Arora Det al [11].

The sero-prevalence of TTIs in the present study was highest for HBV infection (2.14\%). This Finding was similar to study conducted by Chandra et al. [16], Sawke et al [17] and Bhawani etal [18] who havealso found HBV to be the commonest TTI among the donors in different percentages being $1.96 \%, 2.90 \%$ and $1.41 \%$ respectively. The prevalence of $\mathrm{HCV}$ infection in donors was next to $\mathrm{HBV}$ infection being $0.66 \%$ in the present study.

The third highest prevalence of TTI in the present study was HIV being $0.60 \%$. Other studies reported HCV prevalence as $0.34 \%, 0.57 \%, 0.84 \%$ and $1.09 \%$. [16-18] For HIV, India is second only to South Africa in terms of overall number of people living with HIV[15]. The prevalence of HIV in various parts of India is different with high rate in western and southern parts [14]. In the present study the prevalence of HIV in donors was found to be $0.60 \%$. Other studies conducted in various parts of India reported HIV prevalence in donors as $0.23 \%, 0.51 \%, 0.39 \%$ and $0.08 \%$ [16-18].

A WHO report states that the viral dose in HIV transmission through bloodis so large that one HIV positive transfusion leads to death, on an average, after 2 years in children and after three to 5 years in adults. 11 The least prevalence of TTI in the present study was for syphilis being $0.05 \%$. Other studies reported syphilis prevalence in donors as $0.01 \%, 0.23 \%, 0.08 \%$ and $0.90 \%$ [16-19].

\section{Conclusion}

Out of 17640 donors, voluntary donors (78.4\%) were more, in comparison to replacement donors (21.6\%). TTIs were more prevalent in replacement donors than voluntary donors. The number of voluntary donors have decreased from $2008-2010$, but there was male preponderance in both voluntary and replacement donors.

Out of all TTIs, prevalence of HBV (2.14\%) was highest in the donors followed by, HCV $(0.66 \%)$, HIV $(0.6 \%)$, Malaria $(0.14 \%)$ and Syphilis $(0.05 \%)$. The pattern of TTIs among blood donors from 2008-2010 has shown a rising trend for HIV and HCV infections.

Voluntary donation should be encouraged for the prevention of transfusion transmitted infections. Replacement and voluntary donors should be screened thoroughly before blood donation and professional donors should be out rightly rejected.
With the implementation of strict donor selection criteria, use of sensitive screening tests and establishment of strict guidelines for blood transfusion it may be possible to reduce the incidence of transfusion transmitted infection in the Indian scenario.

What this study add to existing knowledge: Since the present study undertaken aimed to review the seroprevalence of blood donors in our hospital.

Being the largest study on replacement and voluntary donors from India, it is likely to reflect changing trends in TTIs in major cities of the country.

Notes: Contribution of different authors;

1. Santosh Meena: Data collection and Compilation.

2. Veena Maheshwari: Manuscript writing.

3. Deepti Gupta: Statistical analysis

Funding: Nil, Conflict of interest: None initiated Permission from IRB: Yes

\section{References}

1.Blood transfusion safety. Available at URL:http:/ /www. who.int/ bloodsafety /en/ Blood_Transfusion_ Safety. pdf. Accessed on June16,2015.

2. Suresh B, Sreedhar Babu KV, Arun R, Chandramouli $\mathrm{P}$, Jothibai DS. Reasons for discarding whole blood and its components in a tertiary care teaching hospital blood bank in South India. J Clin Sci Res 2015;4:213-9. DOI: http: // dx.doi. org/ 10. 15380 /2277-5706. JCSR. 14. 052.

3. Sunderam S, KarirS, HaiderS, Singh S. B, Kiran A. Sero-Prevalence of Transfusion Transmitted Infections among Blood Donors at Blood Bank of Rajendra Institute of Medical Sciences, Ranchi.Healthline Journal 2015; 6 (1):36-40.

4. Sahil Sehgal, P.S Shaiji, Rupinder Kaur Brar. Seroprevalence and Trends of Transfusion Transmissible Infections in Blood Donors in Andaman and Nicobar Islands- An Institutional Retrospective Study. JCDR 2017; 11 (4): EC21-EC24.

5. Millennium Development Goals. http://www.who. int/mdg/goals/en/index.html

6. Voluntary Blood Donation Programme-An Operational Guideline, National AIDS Control Organisation, Ministry of Health and Family Welfare Government of India, New Delhi, India, 2007. 


\section{Original Research Article}

7. A. Ghareh baghian. An estimate of transfusiontransmitted infection prevalence in general populations. Hepatitis Monthly,vol. 11, no. 12, pp. 1002-1003, 2011.

8. Shah N, Shah JM, Jhaveri P, Patel K, Shah CK, Shah NR. Seroprevalence of HBV, HCV, HIV and syphilis among blood donors at a tertiary Care Teaching Hospital in Western India. Gujarat Medical Journal. 2013; 68(2): 35-39

9.Patel PA, Patel SP, Oza HV. Seroprevalence of Transfusion Transmitted Infections (TTIs) in blood donors at Western Ahmedabad-a secondary care hospital based study. Int J Biol Med Res. 2012;3:180610

10. Kulkarni N. Analysis of the seroprevalence of HIV, HBsAg, HCV, \& Syphilitic infections detected in the pre transfusion blood: A short report. Int $\mathrm{J}$ Blood Transfus Immunohematology. 2012;2:1-3..

11. Arora D, Arora B, Khetarpal A. Seroprevalence of $\mathrm{HIV}, \mathrm{HBV}, \mathrm{HCV}$ and syphilis in blood donors in Southern Haryana. doi: 10.4103/0377-4929.64295.

12. Pallavi P, Ganesh CK, Jayashree K, Manjunath GV. Seroprevalence and trends [7]in transfusion transmitted infections among blood donors in a university hospital blood bank: a 5 year study. Indian J Hematol Blood Transfus. 2011;27:1-6.

13. Singh K, Bhat S, Shastry S. Trend in seroprevalence of Hepatitis $\mathrm{B}$ virus infection among blood donors of coastal Karnataka, India. J Infect Dev Ctries. 2009 Jun 1;3(5):376-9.

14. Singh B, Verma M, Kotru M, et al. Prevalence of HIV and VDRL seropositivity in blood donors of Delhi. Indian J Med Res. 2005 Sep;122(3):234-6

15. Pahuja S, Sharma M, Baitha B, Jain M. Prevalence and trends of markers of hepatitis $\mathrm{C}$ virus, hepatitis $\mathrm{B}$ virus and human immunodeficiency virus in Delhi blood donors: a hospital based study. Jpn J Infect Dis. 2007 Nov;60(6):389-91.

16. Chandra T, Kumar A, Gupta A. Prevalence of transfusion transmitted infections in blood donors: an Indian experience. doi: 10. 1258/td. 2008. 080 330 .

17. Sawke N, Sawke G K, Chawla S. Seroprevalence Of Common Transfusion-Transmitted infections among Blood Donors at Bhanpur, Bhopal, M.P. from 20062008. Peoples J Of sci.Research 2010;3(1) 5-7.

18. Bhawani Y, Rao PR, Sudhakar V. Seroprevalence of transfusion transmissible infections among blood donors in a tertiary care hospital of Andhra Pradesh from. 2004-2009. Biology and Medicine 2010; 2 (4): $45-48$.

19. Jasani J, Patel V, Bhuva K, Vachhani A, Patel H, Falleiro JJ. Seroprevalence of transfusion transmissible infections among blood donors in a tertiary care hospital. Int J Biol Med Res. 2012; 3(1):1423-1425.

\section{How to cite this article?}

Meena S, Maheshwari V, Gupta D. Seroprevalence and trends of transfusion transmissible infections among voluntary and replacement donors-an institutional retrospective study. Trop J Path Micro 2018;4(4):330-335.doi:10. 17511/ jopm. 2018.i4.06 